\title{
Desenvolvimento de um sistema de coleta automática de dados agrícolas baseado em rede LoRa e no microprocessador ESP32
}

\author{
Maurício Fernando Lima Pereira $^{1}$, Paulo Estevão Cruvinel $^{2}$ \\ ${ }^{1}$ Instituto de Computação - Universidade Federal de Mato Grosso (UFMT) \\ Av. Fernando Corrêa da Costa, no 2367 - Boa Esperança. Cuiabá - MT - CEP 78060-900 \\ ${ }^{2}$ Embrapa Instrumentação \\ Rua XV de novembro, n 1642 - Centro. São Carlos - SP - CEP 13560-970 \\ mauriciodic.ufmt.br, paulo.cruvinel@embrapa.br
}

\begin{abstract}
This paper presents a data collector system based on the use of a Wi-Fi Lora module from the Heltec Automation(TM). Such on module uses an ESP32 which is a single $2.4 \mathrm{GHz}$ Wi-Fi-and-Bluetooth combo chip designed with the TSMC ultra-low-power $40 \mathrm{~nm}$ technologies. Therefore, it allows the use of both $a \mathrm{Wi}$-Fi and LoRa wireless networks. As one of its main characteristics, which was used in this research, is its applicability for long range with low power consumption. During operation, our receiver node is connected to the Internet, which allows data storage on servers, such as ThingSpeak that is an Internet-of-Things (IoT) analytics platform service The results showed that the connection between the station and receiver was fully functional in controlled environment testing at a distance of 30 meters. Besides, after the conclusion of this advanced data collector, which is still under development, it will be able to allow the interconnection of several stations, even if it is far from the receiver node.
\end{abstract}

Resumo. Este trabalho apresenta a construção de um equipamento de coleta de dados que utiliza os módulos Heltec Wi-Fi Lora 32 para envio de dados através das redes sem fio Wi-Fi e LoRa, a qual tem como um de suas principais vantagens o longo alcance com baixo consumo de energia. O sistema quando finalizado permitirá interligar diversas estações de medição de dados possibilitando que cada equipamento possa de forma independente, enviar suas medições, mesmo estando distante do nó receptor, o qual está conectado a Internet, o que possibilita o armazenamento dos dados em servidores. Os resultados mostraram que a conexão entre a estação e o receptor foram totalmente funcionais em testes em ambiente controlado a uma distância de 30 metros.

\section{Introdução}

O agronegócio é um importante pilar da economia brasileira e nele, como tem ocorrido em diversas áreas, a inclusão cada vez maior da automação vem ganhando destaque em uma área denominada como agricultura de precisão e de decisão. Nesse recente cenário, o uso de máquinas inteligentes guiadas por GPS para plantar, cultivar e colher com precisão está crescendo nas áreas mais avançadas do país, trazendo com isso maior economia de insumos, ganhos de produtividade e sustentabilidade, sendo uma mola propulsora e integradora dentro e fora da cadeia de produção. Além das novas tecnologias embarcadas em 
máquinas agrícolas, o desenvolvimento de estações agrometeorológicas de baixo custo e sua conexão construindo uma rede de sensores tem se mostrado úteis no campo, pois com base nos dados gerados por esses equipamentos, pode-se pode usar técnicas computacionais e estatísticas para se extrair informação útil para o agricultor. Nesse contexto, tem se mostrado importante desenvolver ferramentas computacionais de apoio a decisão, que visem reduzir riscos e consequentemente os prejuízos para o agricultor a partir desses dados. Nesse cenário, como parte de um projeto mais amplo onde se propõem o desenvolvimento de ferramentas de análise de risco agrícola a partir de dados vindos de diferentes fontes, este trabalho apresenta o desenvolvimento de um sistema de coleta de dados agrometeorológicos, que pretende ser uma dessas fontes do projeto. Esse tipo de tecnologia também permitirá construir uma rede de sensores agrícola, baseado em conceitos de IoT e de redes LoRa para se explorar as características de longo alcance e baixo consumo oferecidos por esse tipo de rede [Zhao et al. 2017][Mekala and Viswanathan 2017],[Pham et al. 2016].

Para agilizar a construção de uma primeira versão de equipamento utilizou-se um Arduino Mega 2560, responsável pela conexão com os sensores e um sistema da Heltec Automation denominado Heltec Wi-Fi Lora 32 [Automation 2019], o qual contém numa única placa um microcontrolador ESP32, um transmissor Bluetooth de baixa energia (BLE), um transmissor Wi-Fi e um transmissor LoRa. Essas duas placas trocam dados através de suas portas serias. Utilizou-se um outro módulo Heltec Wi-Fi Lora 32 para de um equipamento de recepção dos dados através de uma rede LoRa. Os dados recebidos por este equipamento são organizados e transmitidos para um servidor remoto através de uma rede Wi-Fi dedicada. Nessa primeira etapa, os dados recebidos das estações estão sendo armazenados na plataforma de serviços Thingspeak, que é plataforma de serviços de análise da Internet das Coisas (IoT) que permite agregar, visualizar e analisar fluxo de dados em tempo real na nuvem. Inicialmente são monitoradas as variáveis climáticas de temperatura e umidade do ar e pluviosidade. A Figura 1 ilustra os conceitos desenvolvidos no trabalho, onde se tem uma estação de coleta com os módulos de microprocessadores, além do sensor DHT22, um pluviômetro de báscula [Boechat et al. 2018] e um anemômetro. A uma distância de aproximadamente 500 metros outro módulo Heltec Wi-Fi Lora faz o papel de gateway, recebendo os dados transmitidos pela estação e os envia para armazenamento no Thingspeak, através da rede Wi-Fi dedicada.

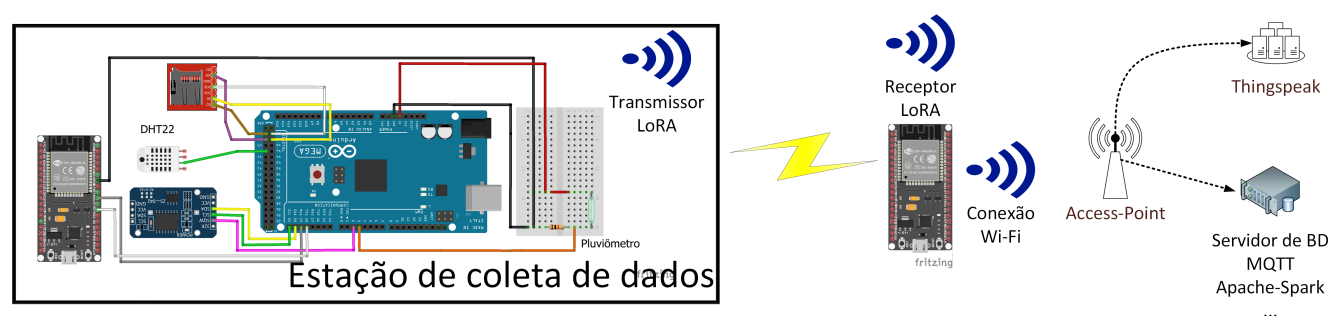

Figura 1. Organização do protótipo de coletor de dados baseado nos módulos Arduino Mega e Heltec Automation usando LoRa para transmissão de dados agrometeorológicos em campo

\section{Materiais e métodos}

As subseções seguir descrevem a organização do experimento em que o equipamento será utilizado futuramente, parte do hardware utilizado na construção do sistema de coleta, da uma breve noção sobre Redes LoRa e apresenta a organização do firmware das estações. 


\subsection{Descrição da área e do experimento onde o dispositivo será utilizado}

Para auxiliar na construção de uma base de dados para validação dos modelos de cálculo de risco, este protótipo do sistema de coleta será utilizado em uma área reservada dentro do Laboratório de Referência Nacional em Agricultura de Precisão (Lanapre) da Unidade da Embrapa Instrumentação Agropecuária, localizada na cidade de São Carlos-SP. A área disponibilizada tem dimensão de 80 metros de largura por 50 metros de profundidade e será totalmente utilizada para plantio de milho. Com objetivo de fazer análise agronômicas e extrair dados, a área foi subdivida em 4 áreas de 20 metros cada. Nessas subáreas serão aplicados diferentes quantidades de Nitrogênio no solo e realizar medidas de solo e das plantas ao longo do tempo. Tal como ilustra a Figura 2, na primeira subárea não será aplicado Nitrogênio ( $0 \%)$, na segunda área $50 \%$ do recomendado na literatura, na terceira $100 \%$ do recomendado e na última $200 \%$. Ao longo dos meses de plantio, serão extraídas em três estádios fenológicos diferentes do milho, serão extraídas amostras de solo, as quais são destacadas na Figura 2, em três diferentes profundidades do solo, sendo elas 1, 2 e 3 metros. Durante todo o tempo do experimento o sistema de coleta será utilizado para obter algumas condições climáticas no campo, com uso de sensores de temperatura, umidade, velocidade do vento e volume de chuva para auxiliar na construção de modelos mais precisos de risco agrícola. O objetivo é integrar essas informações na construção do modelo de análise de risco agrícola.

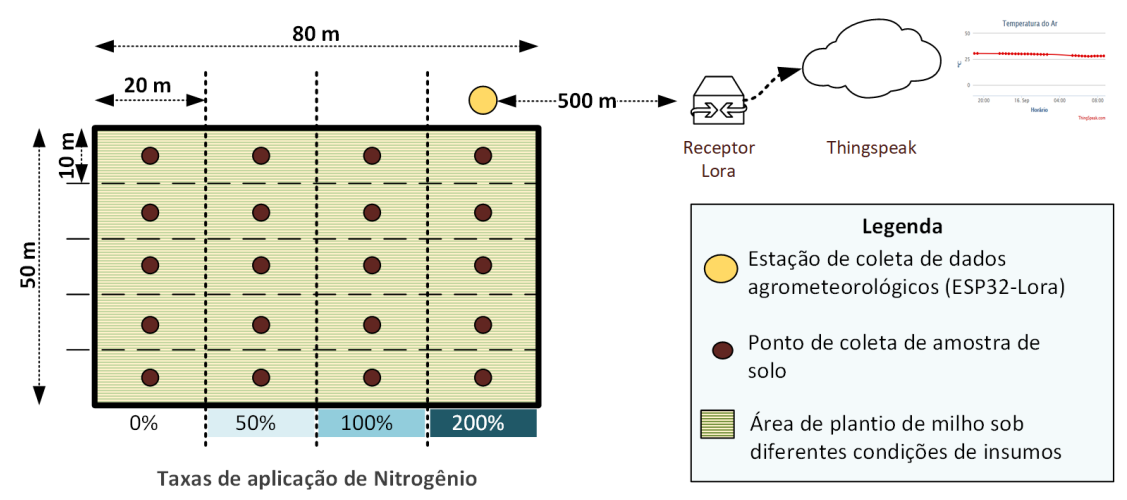

Figura 2. Apresentação do planejamento do experimento com uso da estação agrometereológica em desenvolvimento

\subsection{Módulo Heltec Wi-Fi Lora 32}

O módulo Heltec Wi-F Lora 32, mostrado na Figura 3, destaca-se por possuir um microprocessador ESP32 desenvolvido pela Espressif [Espressif 2019], com arquitetura RISC de 32 bits, duplo núcleo de processamento e núcleo Ultra Low Power. O chip LoRa SX1276/SX1278 [Hareendran 2019] também vem acoplado ao módulo, permitindo conexões usando esse tipo de rede. Além do LoRa existem conexões Wi-Fi e BlueTooth, com as respectivas antenas disponíveis na placa do módulo. Para o LoRa, o módulo disponibiliza uma interface do tipo IPEX para conexão de antena externa.

$\mathrm{Na}$ parte inferior do módulo, existe uma interface de bateria do tipo SH1.25-2 com um sistema integrado para gerenciamento de baterias de Lithium que permite controlar a carga, descarga, proteger contra sobrecarga e trocar automaticamente as fontes de alimentação USB e bateria. Também embutido no módulo, mas em sua parte superior, 
tem-se um display OLED de 0,96 polegadas com matriz de 128 por 64, que pode ser usada para diversas funcionalidades durante a programação/operação.

A fabricante disponibiliza bibliotecas para programação tanto no ambiente nativo do Arduino, quanto para o Platformio e Visual Code.

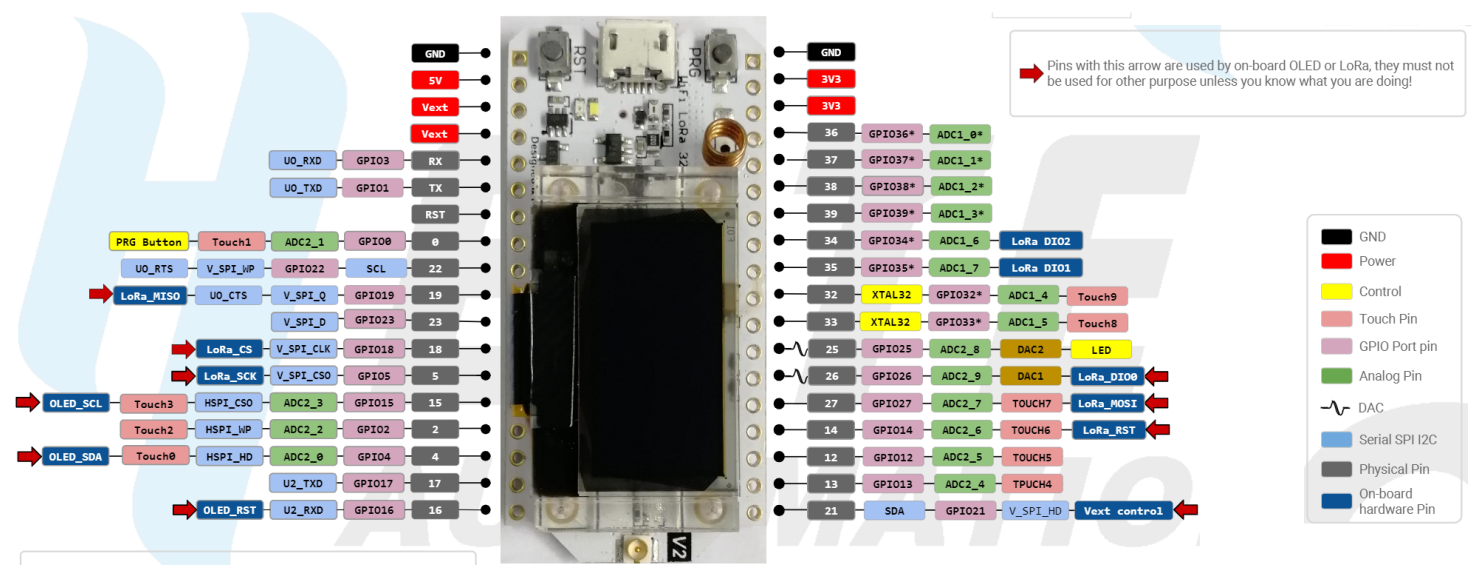

Figura 3. Pinagem do módulo Heltec Wi-Fi 32 Lora

\section{Redes LoRa}

O nome LoRa vem abreviação das palavras Long Range. A rede LoRa é uma solução sem fio em redes abaixo de $\mathrm{GHz}$, em frequências que não demandam licenciamento, como a 433, 868 e $915 \mathrm{MHz}$, por exemplo. É um tipo de rede que está sendo usada para conexão entre dispositivos para aplicações de baixo consumo, longa distância, dado que em campo aberto é possível conseguir até $15 \mathrm{~km}$ de alcance. [Nunes 2017]. De maneira simplificada, o sistema Lora é um módulo colocado nos dispositvos final, como no caso de estação desse projeto, e também em gateways, os quais conseguem fazer com que os dados saiam de uma rede LoRa e através de uma conexão IP atinjam servidores locais e/ou remotos. Os módulos enviam e recebem dados de gateways, de forma similar as redes Wi-Fi, mas com alcance muito maior. Suas principais aplicações são sistema de IoT (internet das coisas) como sensores e monitores remotos (pressão, luz, ligar-desligar, temperatura, umidade, dentre outros), sobretudo aqueles operados a bateria e em alguns casos em locais distantes.

\subsection{Estrutura do firmware da estação coletora}

Na construção do hardware da estação coletora conectou-se todos os sensores, o RTC DS3231 e módulos de memória não volátil no Arduino Mega 2560, deixando as tarefas de comunicação no módulo Heltec Wi-Fi Lora 32. Com isso toda parte de captura de dados foi programada no firmware do Arduino. O princípio nesse firmware foi o de utilizar as portas de interrupção para facilitar o processamento. No caso do pluviômetro, se interrompe sempre que um novo pulso é detectado. Nele, os pulsos ocorrem quando o recipiente dentro dele atinge um volume de aproximadamente $0.25 \mathrm{~mm}$ de chuva, o que movimenta sua báscula e gera um sinal de $5 \mathrm{~V}$ na porta 47 do Arduino, que interrompe a sua atividade para gravação de um flag e incremento na quantidade de pulsos. Nesse mesmo firmware, o DS3231 foi programado para disparar $1 \mathrm{vez}$ por minuto e todos os eventos de captura de dados do DHT22, do anemômetro e organização da informação do 
pluviômetro são orquestrados por esse sinal, que também rege o momento de empacotar as informações e enviá-las via porta serial para o módulo Heltec. Os mesmos dados também são gravados no cartão de memória para maior segurança do sistema.

O módulo da Heltec recebe os dados pela porta serial, inicia a comunicação com o módulo receptor, enviando os pacotes de dados que foram remetidos pelo Arduino. A rede Wi-Fi e BlueTooth desse módulo permanecem desligadas para evitar problemas de consumo.

Já o módulo receptor foi programado para receber dados a todo instante, desempacotar a informação recebida, checar o tipo de dado que foi enviado e mandar para o canal correto do serviço do Thingspeak. Logo após isso envia as confirmações necessárias para a estação que enviou a informação.

\section{Resultados e Conclusões}

Inicialmente foi organizado um protótipo em protoboard do sistema (Figura 4) para validação do hardware e do firmware em laboratório, antes do inicio da construção das placas de circuito impresso e das caixas que serão utilizadas em campo. Nos testes módulos de captura e o de recepção foram colocados a uma distância de 30 metros, com paredes entre os dois módulos. Nos testes realizados a essa distância, observando os dados gravados no cartão e os dados de log da recepção, percebe-se que não ocorreu perda de informação. Eventualmente ocorreram falhas de envio na transmissão do receptor e a plataforma Thingspeak. Melhorias no código para permitir o reenvio e checagem da rede Wi-Fi foram propostas para tentar reduzir a quantidade de falhas ocorridas.
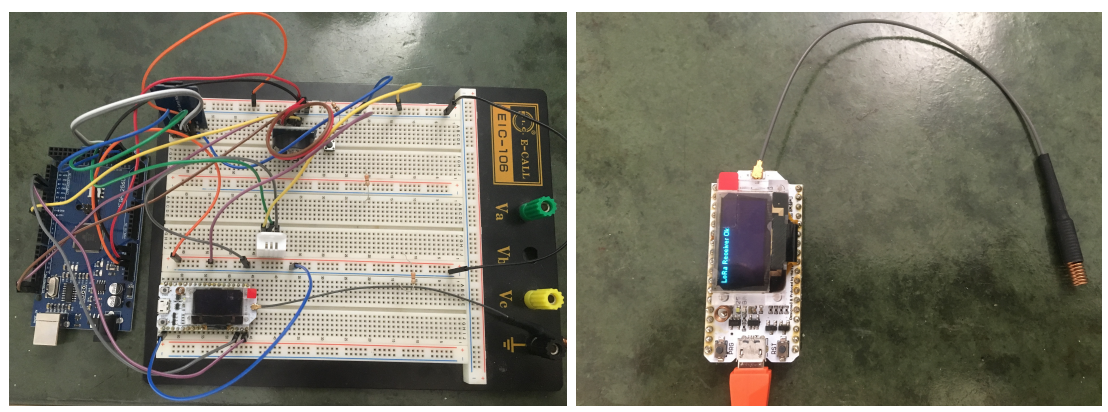

Figura 4. Protótipos desenvolvidos para captura e transmissão dos dados
através de uma rede LoRa, tendo a esquerda a estação coletora, ainda
em protoboard, e a direita o módulo receptor

Realizando um teste do sistema com 12 horas de funcionamento, foi possível gravar no Thingspeak dados que já podem ser analisados com as ferramentas desse serviço. Os gráficos na Figura 5, mostram o resultado do teste. Percebe-se que alguns dados, corretamente enviados na rede LoRa, não foram retransmitidos ao Thingspeaks. A avaliação dessa primeira versão do sistema, é de ele funcionou satisfatoriamente nos testes de laboratório, porém algumas correções de firmware ainda precisam ser implementadas para aumentar a confiabilidade do sistema. Como não existem problemas de conexão entre os módulos e os sensores, os próximos passos serão a construção da placa definitiva, a acomodação em caixas resistentes às intempéries e a utilização na área da Embrapa 

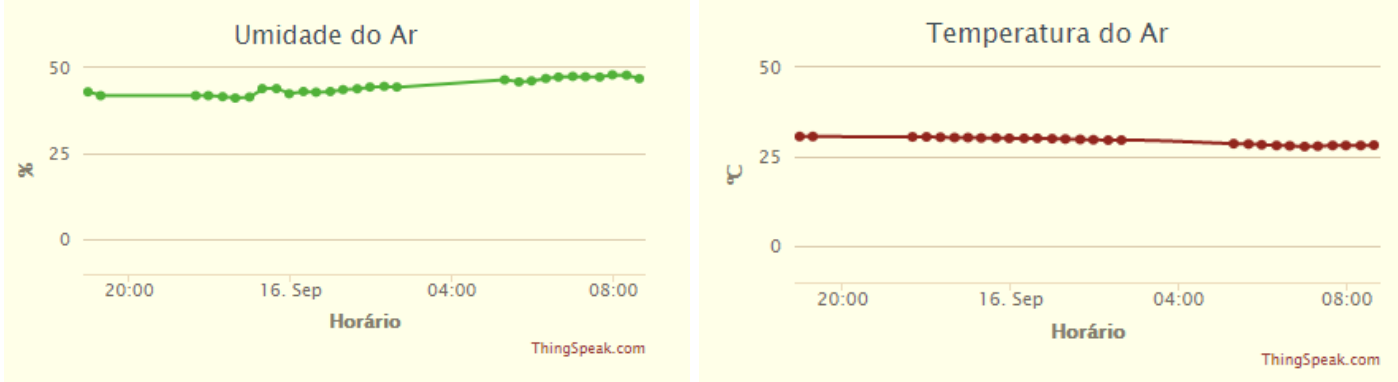

Figura 5. Apresentação do planejamento do experimento com uso da estação agrometeorológica em desenvolvimento

Instrumentação Agropecuária disponibilizada para o experimento. Pode-se afirmar que o uso de rede LoRa até o momento se mostrou bastante confiável.

\section{Agradecimentos}

Este trabalho recebe apoio financeiro da Fundação de Amparo à Pesquisa do Estado de São Paulo (FAPESP), Processo 17/19350-2, via convênio que envolve a IBM Brasil e a Empresa Brasileira de Pesquisa Agropecuária (Embrapa). Os autores também agradecem o apoio institucional da Universidade Federal de Mato Grosso (UFMT).

\section{Referências}

Automation, H. (2019). Wifi lora 32. Disponível em https://heltec.org/project/wifi-lora$32 /$.

Boechat, J. C., Pereira, M. F. L., and Dantas, O. M. (2018). Pluviógrafo de baixo custo para coleta e transmissão sem fio de dados de chuva, usando o protocolo mqtt. In Anais da IX Escola Regional de Informática de Mato Grosso, pages 48-57, Barra do Bugres.

Espressif (2019). Esp32 series datasheet. Disponível online em "https: //www.espressif.com/sites/default/files/documentation/ esp32_datasheet_en.pdf".

Hareendran, T. (2019). A review of the mini sx1278 lora transceiver module. Disponível em https://www.electroschematics.com/14383/rf-radio-frequency/.

Mekala, M. S. and Viswanathan, P. (2017). A survey: Smart agriculture IoT with cloud computing. In 2017 International conference on Microelectronic Devices, Circuits and Systems (ICMDCS). IEEE.

Nunes, B. (2017). Introdução a lora, nb-iot e sigfox. Disponível online em https://www.embarcados.com.br/lora-nb-iot-e-sigfox/.

Pham, C., Rahim, A., and Cousin, P. (2016). Low-cost, long-range open IoT for smarter rural african villages. In 2016 IEEE International Smart Cities Conference (ISC2). IEEE.

Zhao, W., Lin, S., Han, J., Xu, R., and Hou, L. (2017). Design and implementation of smart irrigation system based on LoRa. In 2017 IEEE Globecom Workshops (GC Wkshs). IEEE. 